SECTION D

\title{
DIAPHRAGMS IN SEISMIC RESISTANT BUILDINGS
}

\author{
D. Kolston and B.W. Buchanan
}

\begin{abstract}
:
The paper deals with the design requirements for reinforced concrete diaphragms. Although diaphragms are primary members of the seismic force resisting system, ductile detailing of diaphragms is not considered to be required. While the design of diaphragms in regular framed buildinas is straightforward, the analysis of transfer diaphragms involves more complex design criteria. special considerations related to precast diaphragms are dealt with in more detail.
\end{abstract}

\section{INTRODUCTION:}

For the purposes of this paper, diaphragms are defined as structural members which distribute seismic forces to the horizontal force resisting system. The paper is confined to reinforced concrete diaphragms, both cast-in-situ and precast, and includes situations where in-situ toppings are laid on prestressed floor units.

In seismic codes, diaphragms are generally (and appropriately) listed as primary members of the seismic force resisting system, and as such they have to be carefully considered in the design of the total structure.

The function of diaphragms is of a different nature from that of other primary members of the earthquake load resisting structures such as beams, columns and walls. In any design for forces below the expected elastic response levels, some of the primary members - beams, columns or shear walls must dissipate seismic energy. But no such action is (or should be) required of diaphragms. Consequently the special seismic detailing requirements which apply to ductile walls and which have been established to ensure 'adequate ductility', are not required.

It is, however, essential that the assumptions as to diaphragm strength and stiffness, adopted in the primary analysis of the building, can in fact be provided by the diaphragms. It is considered that the strength and detailing requirements which apply to gravity load carrying structures are generally adequate for this purpose.

\section{TYPES OF DIAPHRAGM:}

In practice there are basically two categories of diaphragm, differentiated by whether they are, or are not, required to re-distribute seismic forces between vertical structural elements.

\section{Type 1: Simple Diaphragms}

These are diaphragms which are required only to distribute the horizontal seismic forces generated at their own level to the elements of the horizontal seismic force resisting system. This condition will be realised only when the building is regular and without significant discontinuity in the structural system.

Loads are obtained from the Loadings Code and the forces resulting from these loads are established from basic static considerations.

If the primary elements are of unequal stiffness, the calculation of the diaphragm forces requires consideration of relative stiffnesses.

Diaphragms of more complex shape e.g. having re-entrant corners, cutouts, etc. should have additional reinforcing in critical areas to reduct the local damage which could otherwise result from the low design loads permitted in the Loadings Code.

\section{Type: Transfer Diaphragms}

This type of diaphragm is required to transfer or redistribute, at its own level, seismic forces generated at other levels. The forces can become very large when there are significant discontinuities in the horizontal seismic force resisting system. The classic example of this type of diaphragm is the roof slab of a rigid podium building above which rises a flexible framed tower structure (figure 1). Another case is shown in figure 2(a). Note that in some situations, e.g. as in figure 2 (b), the transfer diaphragm ensures the overall stability of the building.

In cases where the redistribution of forces at the transfer level is relatively insianificant, (say about $20 \%$ of the total seismic shear force,) the transfer level diaphragm may be designed as a type 1 diaphragm.

\section{DESIGN FORCES :}

\section{Type 1 Diaphragms}

Design forces are to be found from the 'Parts of Portions of Buildings' section of the Loadings Code (Ref. 1). The total force $\mathrm{F}_{\mathrm{p}}$ on the diaphragm is 


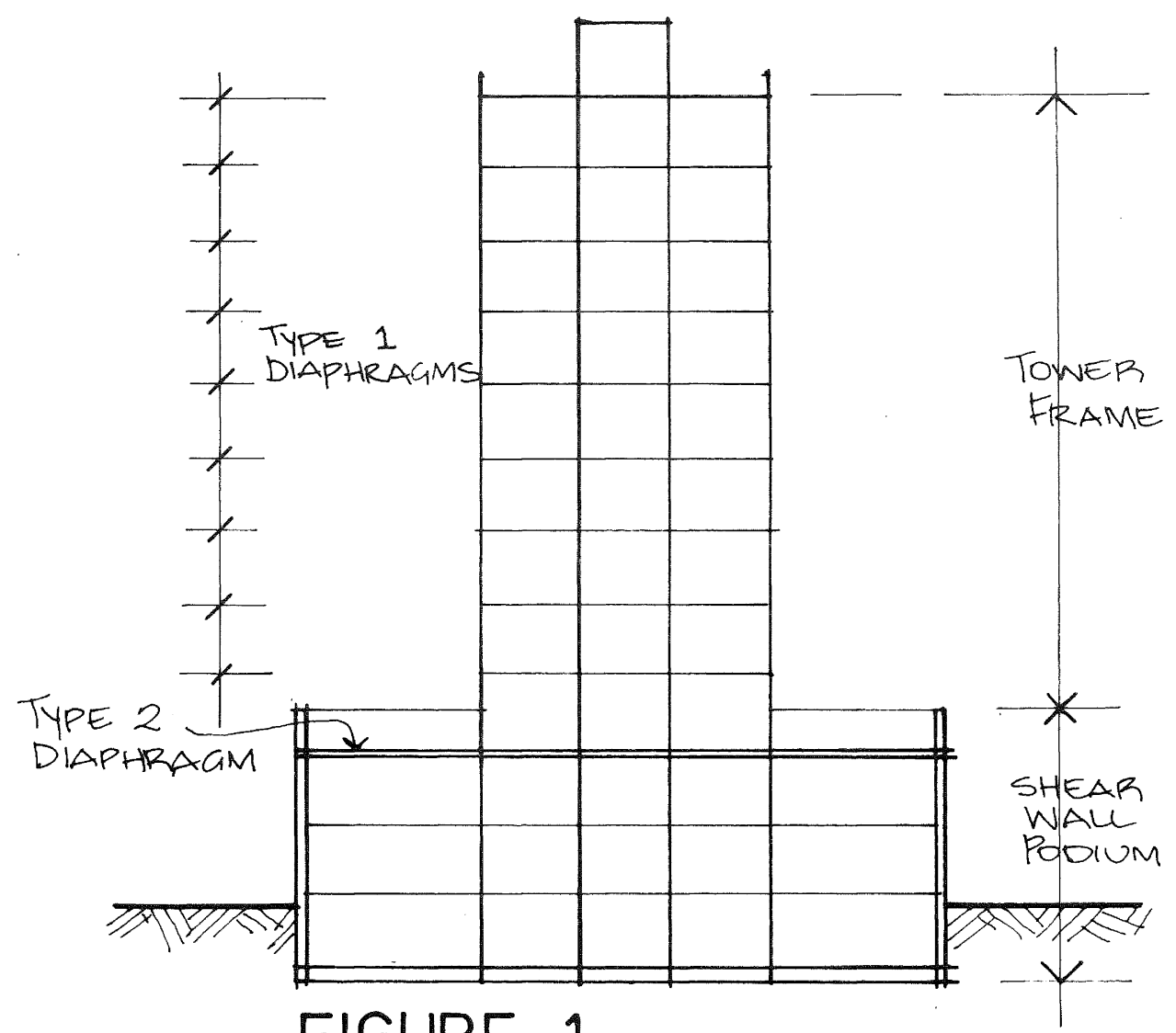

FIGURE 1.

Transfer Diaphragm in TowerPodium Building.

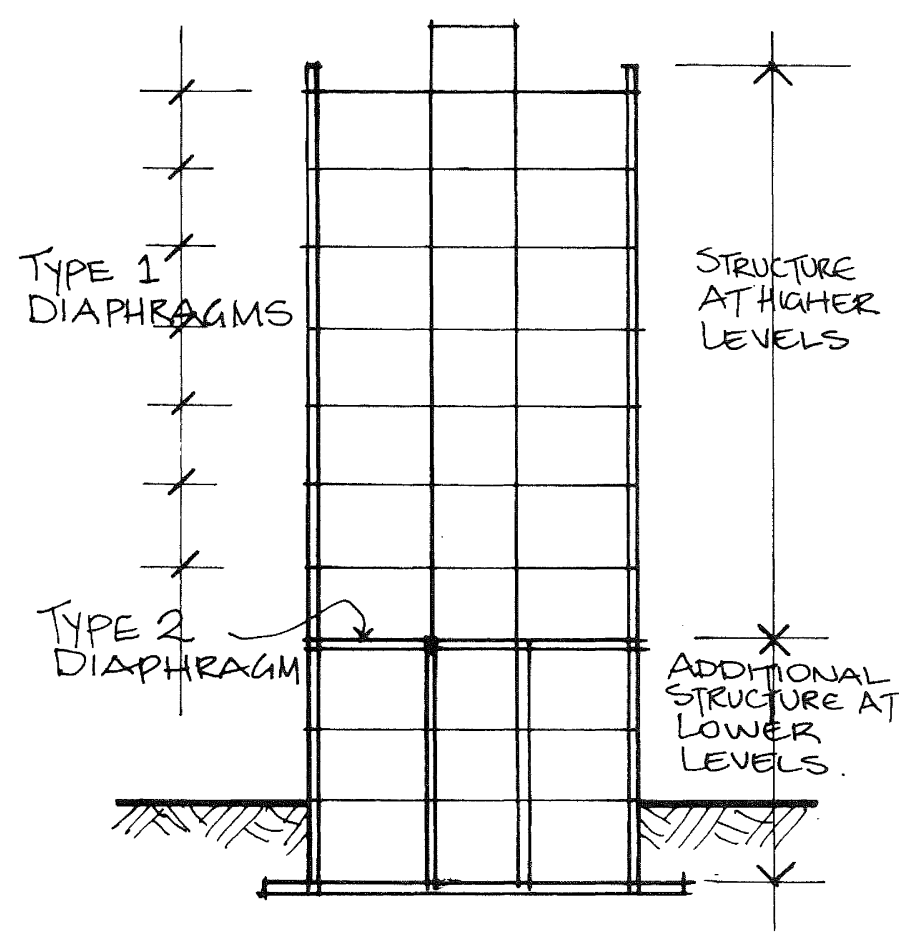

FIGURE 2. (a)

Transfer Diaphragm in a Building where a change of Structure occurs

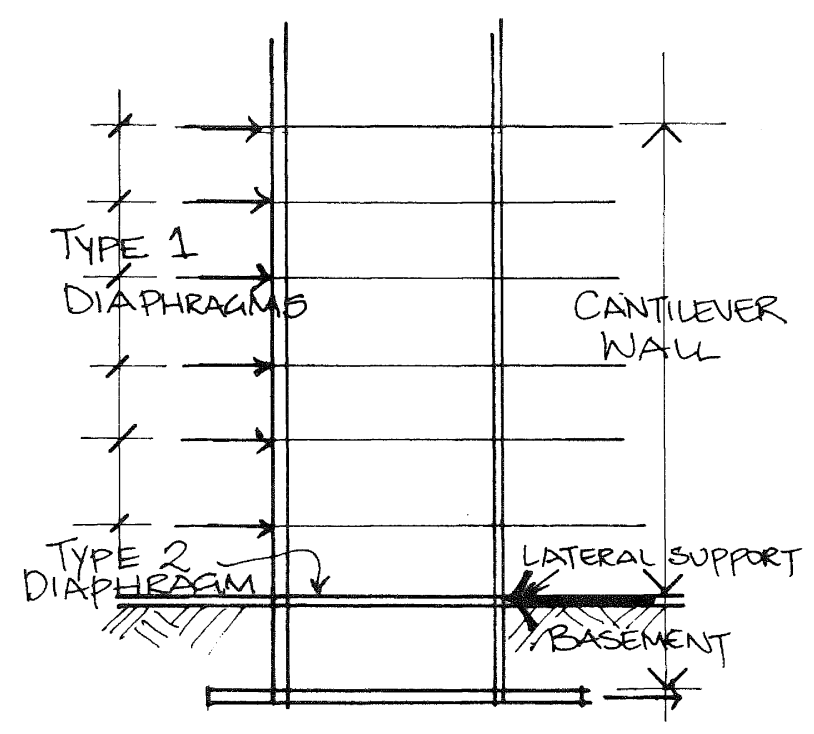

FIGURE 2(b)

Base fixity for a clamped cantilever wall. 
obtained from the formula

$$
F_{p}=C_{p} . \quad W_{p} \quad(D-1)
$$

where

$$
\mathrm{C}_{\mathrm{p}}=\underset{\text { the seismic design force }}{\text { coefficient }}
$$

and $W_{p}=$ the seismic load which the diaphragm distributes to the vertical elements.

(This is the tributary storey load, including the seismic live load, for the diaphragm considered).

In Zone $A$, for class III buildings, $\mathrm{C}_{\mathrm{f}}$ is 0.2 for single storey structures and 0.3 for multistorey structures.

To qualify for these relatively low $C$ factors, the only stipulation in the cBmmentary to the Loadings code is that reinforced concrete slabs shall be reinforced in two directions"... at reasonably close spacings".

It should be appreciated that, for a relatively tall, uniform, multistorey building with S.M.I.R. = 1 and a basic co-efficient $\mathrm{C}$ of 0.15 , the $\mathrm{K}$ factor at the top will be nearly 2.0. $x$ This will give a primary seismic coefficient of nearly 0.3 on all masses at the top.

Thus the 'parts' coefficient for the roof level diaphragm, set at 0.3 , is for that building, no greater than the coefficient for the design of the primary structure. Clearly, if the S.M.I.R. product is greater than 1.0 , the primary seismic coefficient at the top will be greater than 0.3 . On the other hand, the Loadings Code requires increased diaphragm coefficients only when I exceeds 1.0. The low diaphragm coefficient and the absence of any requirement to modify for $S, M$ and $R$ factors, is apparently done deliberately and helps to avoid possible complications such as increasing perimeter beam capacities with resulting increased column design moments and increased joint shear.

Such low coefficients can be justified by the fact that diaphragms designed for similar coefficients have generally performed satisfactorily in earthquakes. For these simple diaphragms, some yielding is unlikely to affect the overall response or the performance of the structure, and can therefore be accepted.

\section{Type 2 Diaphragms}

A transfer diaphragm must cope with two sets of design forces, namely those arising from its simple diaphragm function requiring distribution of the forces $F_{p l}$ generated by masses at its own level, pl and the, usually much larger, forces, $F$ required to be redistributed due to chafiges in stiffness in the primary lateral load resisting system.
In buildings requiring type 2 diaphragms, the behaviour of the primary elements is very much dependent on the transfer diaphragm maintaining its assumed strength and stiffness throughout any seismic attack.

Accordingly, these diaphragms should be designed for forces $F_{2}$ corresponding to the probable yield capacity of the primary system.

At any lesser strength level, not only would the behaviour of the primary vertical elements be put at risk, but the diaphragm itself would be taken into the inelastic range. The diaphragm may behave very poorly in the inelastic range because of its slender shape and lack of detailing for non lineair behaviour and in any case, there are neither test data nor established design rules which could be used for this condition.

In some special cases, such as buildings with many more walls than required for seismic resistance, a special study may justify a less conservative approach.

The actual forces in any vertical member are seldom determinate, being affected by uncertainties of relative stiffness ( even before yielding) and by uncertainties of mode of seismic response and of actual member strengths. However, it is reasonable to base the diaphragm design on the maximum shears likely to be developed in the vertical elements, i.e. the final design shears.

In determining these forces, it will usually be easier to consider the input from members above the diaphragm concerned as being the design input forces, regardless of whether the building has members 'starting' or 'stopping' at the transfer level.

For walls designed to section B of these papers, the design input force should be taken as being the same as $\mathrm{V}_{\text {wall' }}$, in which

$$
\mathrm{v}_{\text {wall }}=\omega_{\mathrm{v}} \phi_{\mathrm{O}} \mathrm{v}_{\text {code }}
$$

where

$\begin{aligned} & \mathrm{V}_{\text {code }}= \text { the shear demand derived from } \\ & \text { the code loading }\end{aligned}$ $\phi_{0}=\begin{aligned} & \text { the moment capacity overstrength } \\ & \text { factor }\end{aligned}$

and $\omega_{v}=$ the dynamic shear magnification
factor

For frames above the transfer level, the design force can be taken as the final design shear forces in the columns. Appropriate force levels are given in the paper "Columns - Evaluation of Actions" by T. Paulay (Bulletin of N.Z.N.S.E.E. Vol. 10, No.2, June 1977).

Because a safe design force for $\mathrm{F}_{\mathrm{pl}}$ is extremely difficult to determine with any degree of confidence, it is 


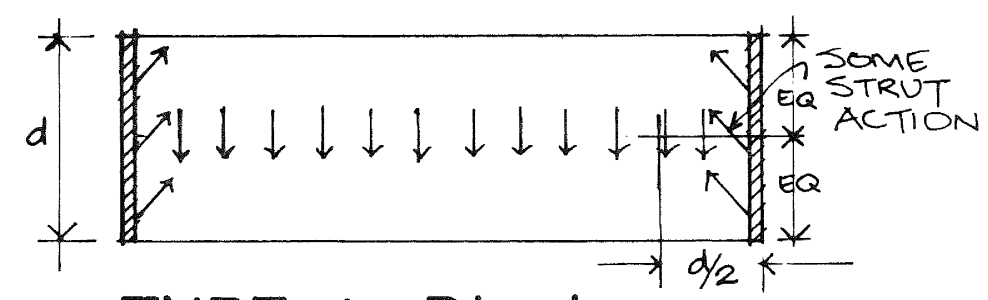

TYPE 1 Diaphragm (a)

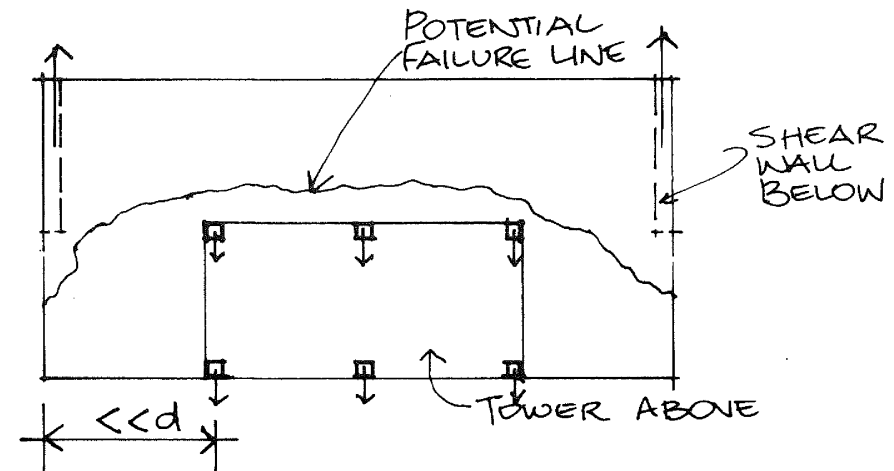

TYPE 2 Diaphragm

(b)

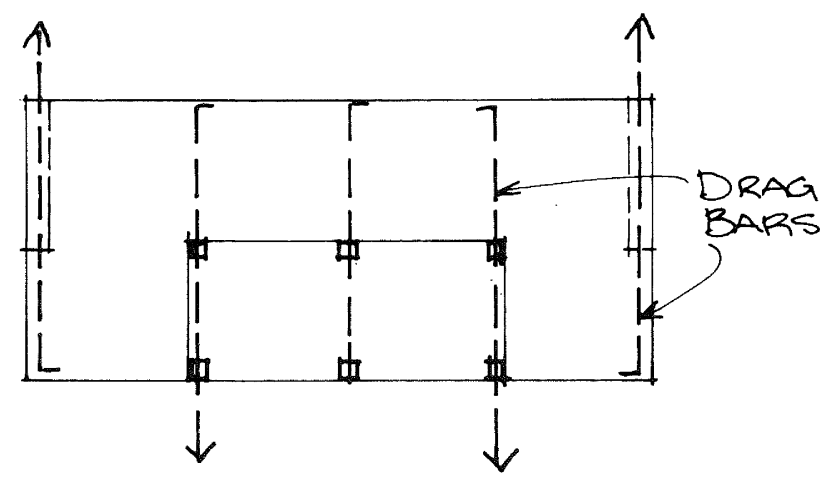

TYPE 2 Diaphragm with 'Drag Bars.'

\section{FIGURE 3. (c)}

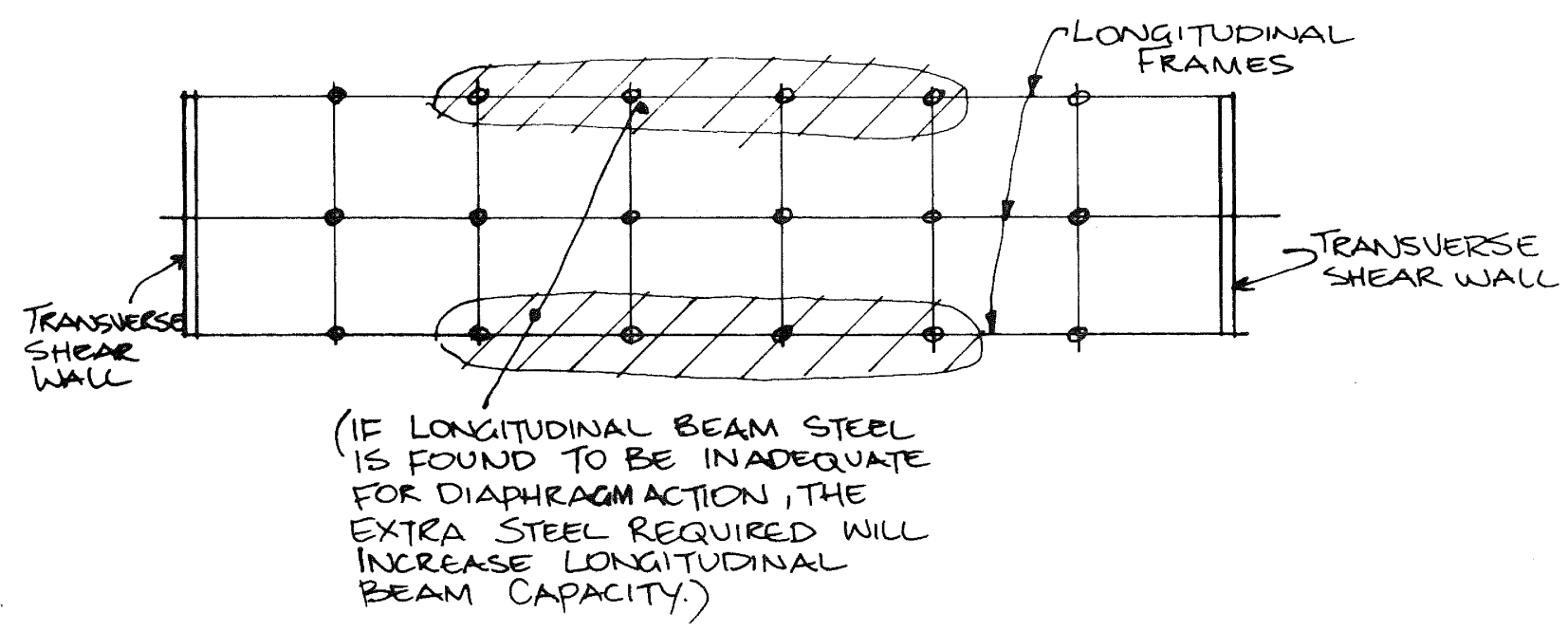

FIGURE 4.

Diaphragm spanning between widely spaced shear walls. 
suggested that Loadings Code $\mathrm{Cp}$ values simply be increased by a factor. It is suggested that a value of at least 2 for this factor would be appropriate. In practice this design force would still be quite small in comparison with the design force $F_{p}$.

It should be noted that the transfer of forces is unlikely to take place only within the diaphragm at the level of the discontinuity - one or more diaphragms below the primary transfer level will usually also act as transfer diaphragms. It is preferable to design on the basis of a properly evaluated distribution of loads utilizing several transfer levels. Alternatively, it may be reasonable to design only one transfer diaphragm and to review the ability of the other diaphragms to perform their primary load carrying functions under the resulting distortion. In any case it is important to recognise that any participation of lower diaphragms, whether intended or not, will invariably increase the shear in the vertical load carrying members, and this must always be designed for.

\section{Torsional Effects}

When establishing diaphragm design forces, the actual building eccentricities which will cause torsional effects on the diaphragm and the forces resulting therefrom, will automatically be available for the diaphragm design.

But what needs to be considered is the extent to which the further requirements of the Loadings Code, i.e. the allowances for amplification and accidental torsion need to be incorporated in diaphragm design.

The loadings required in the Loadings Code for the design of type 1 diaphragms have been deliberately set at an arbitrary low level as indicated in the section on 'Type I Diaphragms!. Application of further design refinements do not appear to be justified in these circumstances and type 1 diaphragm design does not require consideration of the Loadings Code torsion equations.

In the case of a transfer diaphragm, the design as described above in 'Type 2 Diaphragms' for the design shear forces in the primary elements provides a reasonable upper design limit which would not be exceeded by a code lateral loading or code torsional effect.

\section{DESIGN STRENGTH :}

\section{General}

Traditionally, diaphragms have not been detailed in accordance with the requirements for ductile detailing of other reinforced concrete members but have nevertheless generally performed satisfactorily.

The design forces for type 1 diaphragms are less than those which may occur during a seismic disturbance and some yielding of the diaphragm is to be anticipated. Because the diaphragm is not a primary energy dissipating element, and will not normally have to develop high compression strains, special seismic detailing is not considered to be necessary.

Diaphragms should be designed for the horizontal forces of the section on Design Forces and it is not considered necessary that gravity loads need be combined with these forces when designing the daiphragm. The fundamental difference in effect resulting from gravity loads and dynamic horizontal seismic attack makes it doubtful whether a combination of these loads would be appropriate. All reinforcing within the diaphragm, including slabs, beams and ribs may be utilized for diaphragm action, provided this steel is properly lapped and effectively anchored for the diaphragm forces involved.

\section{Shear Strength}

The shear design of diaphragms cannot be treated as the shear design of beams because of the way the loads are applied and resisted. The degree of internal arch action normally considered in the end region of beams is likely to be limited or to be entirely absent.

In type 1 diaphragms both the load and the support reactions would normally be distributed across the full depth of the section as illustrated in figure $3 a$, and might be considered to be equivalent to resultant load and reaction on the midline. For such a loading it would appear appropriate to calculate the critical shear at a distance of $d / 2$ rather than the normal d from the 2 end.

The diaphragm forces will be applied in alternate directions, and in the case of non-symmetrical primary elements, direct tensions could be produced within the diaphragm without any arch action. Figure $3(b)$ shows such a situation for the case of a transfer diaphragm. ('Drag bars' as shown in figure $3(\mathrm{c})$ can be provided. These will restore the arch action and prevent a tension type failure).

The design should then follow the Concrete code in which

$$
v_{i}=\frac{v}{\phi b d}
$$

and $\mathrm{V}=$ the design shear force

$\phi=0.85$

$\mathrm{b}=$ the minimum slab depth

$\mathrm{d}=0.8 \ell_{\mathrm{w}}$ where $\ell_{\mathrm{w}}$ is the width of the diaphragm.

There is no conclusive literature available which gives guidance on the buckling of diaphragms under simple shear loading and certainly none covering 
simultaneous vertical excitation. However from consideration of the compression strut action associated with shear, in conjunction with gravity loading of the diaphragms, such buckling is unlikely to occur when shear stresses are below $0.5 \sqrt{f^{\prime} c}$ or when the slenderness ratio $\mathrm{kl} / \mathrm{d} / \mathrm{r}$ in the direction of the span of the slab $u / r$ is less than 70. In the unlikely event of both of these limits being exceeded, buckling should be investigated in detail.

\section{Flexural Strength}

The required flexural strength of the diaphragm should be determined from the design forces in the section on Design Forces.

Generally, diaphragms have the proportions of deep beams and the appropriate recommendations in the concrete Code and Commentary should be followed, in particular the commentary reference to Park, R. and Paulay, T., "Reinforced Concrete Structures". (Ref. 2).

There is no evidence from earthquake damage to suggest that the diaphragm steel needs to be designed on the basis of concurrent attack. In fact, as discussed in 'Type I Diaphragms', large quantities of diaphragm flange reinforcement would have undersirable effects on frame design. Consideration of concurrency effect is therefore not recommended and, at worst, this procedure will possible increase the ductility demand on the beams and the diaphragm slab.

Figure 4 shows an example of a building type where the necessary longitudinal steel for diaphragm action might exceed the steel required for frame action, thus increasing the longitudinal beam capacity. This affects the capacity design of the longitudinal frames, and is one of the reasons why the Loadings code coefficient for diaphragms is set relatively low.

Buckling of the compression zone of the diaphragm needs to be considered. In the design of type 1 diaphragms, compression flange buckling is unlikely to require detailed investigation where there is an edge beam.

Otherwise the buckling problem should be investigated as discussed for ductile shear walls in section B. If the compression areas exceed the limits set in section $B$, the edge should be stiffened to comply with these limits. For type 2 diaphragms, which are designed for the maximum expected forces, adequacy of edge stiffness may instead be examined according to traditional theories of elastic instability.

\section{OPENINGS IN DIAPHRAGMS:}

In type 2 diaphragms, the definition of the loads results in a safe upper limit of design loads, whereas in type 1 diaphragms, the actual building response could produce loads in the diaphragms appreciably greater than those provided for in the design.

It is therefore important that at an early stage of the design process, any large holes and slots are arranged to be sufficiently distant from the edge of a diaphragm to provide an adequate area to take the maximum induced compression. It is suggested that such a check be done with only the design load in the case of type 2 diaphragms, but with at least double the Code design load in the case of type 1 diaphragms.

Where the available compression area consists of a beam which is only just adqquate for these loads, confinement of the beam section and ductile detailing should reduce damage in the event of overload.

If an adequate compression area cannot be provided, the holes should be considered to extend to the edge of the diaphragm and the remainder of the slab designed and detailed accordingly. The possible resulting damage to the neglected outer concrete needs to be considered.

Substantial openings require a detailed structural analysis of the remaining slab in their vicinity. It is not considered adequate to provide nominal trimmer bars.

The low Code loadings for type 1 diaphragms assume a reasonably uniform distribution of inelastic strains within the diaphragm. Large holes located in areas where the diaphragm moment is greater than $50 \%$ of the maximum moment could produce local concentrations of large strains which could invalidate this assumption. It is therefore advisable to design such areas for higher than code loads. It is suggested that twice Code loads be used.

\section{CONSTRUCTION JOINTS:}

Construction joints across diaphragms are not likely to be subject to critical stresses unless there are large openings present along the jointline.

At construction joints, the amount of reinforcing should be determined on a shear friction basis as set out in the concrete code.

The minimum area of reinforcement $A_{V f}$ required across the joint is given by:

$A_{v f} \geqslant \frac{V}{\phi f y \mu}$

where

$\mathrm{V}=$ design shear force

$\phi=$ strength reduction factor $=0.85$

$f_{y}=$ specified yield strength of the reinforcement

$\mu=$ coefficient of friction $=1.0$

All other requirements in the Concrete Code related to construction joints and shear friction design also apply. 
The reinforcement ratio should not be less than 0.0025 for grade 275 reinforcement.

\section{CONNECTIONS TO STRUCTURE:}

In all cases there must be a proper connection between the diaphragm and the structure to ensure a continuity of load path. Wherever a construction joint is likely or permitted to occur, transverse steel should be provided on a shear friction basis. When diaphragms incorporate precast units, special attention should be given to these connections. Particular difficulties can arise when units are continuous over parts of the primary structure, requiring the introduction of insitu reinforced concrete connectors.

\section{DIAPHRAGMS INCORPORATING PRECAST ELEMENTS:}

While the seismic actions on precast diaphragms are the same as on in-situ slabs, the behaviour of such diaphragms can be much less satisfactory, depending on the detailing employed.

In-situ slabs have generally performed well during earthquakes but inadequately connected precast units, without a structural topping, have a poor seismic record.

A continuous in-situ topping over precast units can readily provide a satisfactory diaphragm whereas the integration of a series of precast units as a diaphragm requires special detailing.

\section{PRECAST UNITS WITH IN-SITU TOPPING:-}

\section{General}

Most precast systems require an integral concrete topping to provide a section sufficient to support the gravity loading in composite action. Such a topping slab can be utilised as the diaphragm for the distribution and transfer of seismic loads.

The Concrete code contains minimum requirements designed to ensure composite action for gravity loads with steel ties between topping and precast elements being required. when the interface gravity shear stresses exceed certain limits. For diaphragm action ties might also be required to ensure adequate diaphragm performance.

For reliable diaphragm action, it is desirable to have the topping slab connected to the precast system by a distributed pattern of steel ties, adequately anchored into both components. Such ties remove many of the uncertainties which exist regarding the bonding of the topping to the precast surface arising from concern as to the adequacy of surface preparation, adequacy of curing and standards of general construction practices. They also provide positive safeguards against buckling, for which design criteria are not easily established due to lack of data on vertical earthquake effects. deformation of slabs due to twisting, rocking of shear walls etc.

Detailed Requirements

Many slabs rely on composite action for the support of gravity loads. Code requirements will then determine whether steel ties have to be provided for that purpose. The only circumstance where that Code does not require steel ties for composite action is when shear stresses on the horizontal interface are low and the surface of the units is intentionally roughened and clean.

(It is considered to be good practice to provide ties if the precast system without composite action is unable to carry at least $1.0 \mathrm{D}+0.25 \mathrm{~L}$ (or $1.0 D=L_{R}$ for storage occupancy) ).

When diaphragm stresses $v_{j}$ are less than $0.20 \sqrt{f^{\prime C}}$ and with surfaces roughened and clean to the standards required by the concrete code, it is acceptable to rely on bond between concrete surfaces to prevent separation and buckling. These stresses should be calculated on the basis of the topping alone resisting the seismic diaphragm shear. If these stresses exceed 0.20 $\sqrt{f^{\prime} c}$, and in cases where the roughening and cleaning provisions of the code for composite action are not complied with, steel ties should be provided between the topping and the units or in-situ ribs.

When type 2 disphragms are critical to the proper structural behaviour of the building, it is considered advisable to provide steel ties in any case. Where ties are required, and for a $65 \mathrm{~mm}$ thick topping, these ties should be spaced at not more than $1500 \mathrm{~mm}$ centres each way and the effectiye area of tying steel shoula be $40 \mathrm{~mm}^{2} / \mathrm{m}^{2}$ of tributary floor area.

For thicker

slabs, the tie centres may be increased proportionally to the thickness, but the tie ratio should be increased proportionally to the slab thickness required for diachragm action.

The topping thickness should be sufficient to ensure adequate covers at all points, including at beams. The minimum thickness for a structural topping should be $65 \mathrm{~mm}$. Reinforcing in the topping should be sufficient to satisfy design bending and shear requirements and in any case not less than the code minimum for suspended floors. Splices in reinforcing should be capable of developing the full tension capacity of the reinforcing.

\section{PRECAST DIAPHRAGMS WITHOUT IN-SITU TOPPING:-}

For these diaphragms, the connections between the units require special design consideration.

With cast in place strips of in-situ concrete, code requirements regarding construction joints, minimum steel and full tension splicing apply. 
When slabs are connected by welded or bolted connections, the assemblages does not constitute a slab "reinforced at close centres in both directions", and therefore does not qualify for item I of Table 8 of the Loadings Code and the $S$ factor should be increased to that of item 3 of the table, i.e. $S_{1}=2$, resulting in a $C$ factor of 0.6 at the top level $p_{\text {of }}$ ax multistorey class III building.

The ductility demand on the connections should be further reduced, in accordance with good practice for any connection in concrete construction, by applying a multiplying factor of 2 to the design load of the connections themselves.

Because of the evidence of unsatisfactory seismic performance of welded or bolted connections and because of the uncertainty in establishing the loads to be resisted, such connections should not be used in type 2 diaphragms which fulfil a crucial function in the structure.

Lateral load distribution in precast slabs by way of a Vierendeel action has been attempted by some designers. Such a procedure is not intended by any of the Loadings Code coefficients, nor do the recommendations in this paper relate to such designs.

\section{NOTATION:}

All lengths are in $\mathrm{mm}$, areas in $\mathrm{mm}^{2}$, forces in $\mathrm{N}$, moments in $\mathrm{N}-\mathrm{mm}$ and stresses in MPa.

$$
\begin{aligned}
& A_{V f}=\text { area of shear friction reinforcement } \\
& \mathrm{b}=\text { minimum slab thickness } \\
& \text { C = basic seismic coefficient } \\
& c_{p}=\text { seismic design coefficient for } a \\
& \text { part or portion of a building } \\
& \mathrm{C}_{\text {pmax }}=\text { maximum value of } \mathrm{C}_{\mathrm{p}} \\
& \text { D } \quad=\text { dead loads } \\
& \mathrm{d}=\text { reduced depth of the diaphragm }=0.80 \mathrm{l}_{\mathrm{W}} \\
& \mathrm{F}_{\mathrm{p}} \quad=\text { the horizontal force on a part or } \\
& \text { portion of a building } \\
& \mathrm{F}_{\mathrm{pl}}=\text { horizontal diaphragm forces generated } \\
& \text { by masses at the level of the } \\
& \text { diaphragm } \\
& \mathrm{F}_{\mathrm{p} 2}=\text { horizontal diaphragm forces which } \\
& \text { are redistributed by a transfer } \\
& \text { diaphragm } \\
& f^{\prime}{ }_{C}=\text { specified compressive strength of } \\
& \text { concrete } \\
& \mathrm{f}_{\mathrm{y}} \quad=\text { specified yield strength of } \\
& \text { reinforcement } \\
& \text { I = importance factor as defined in }
\end{aligned}
$$

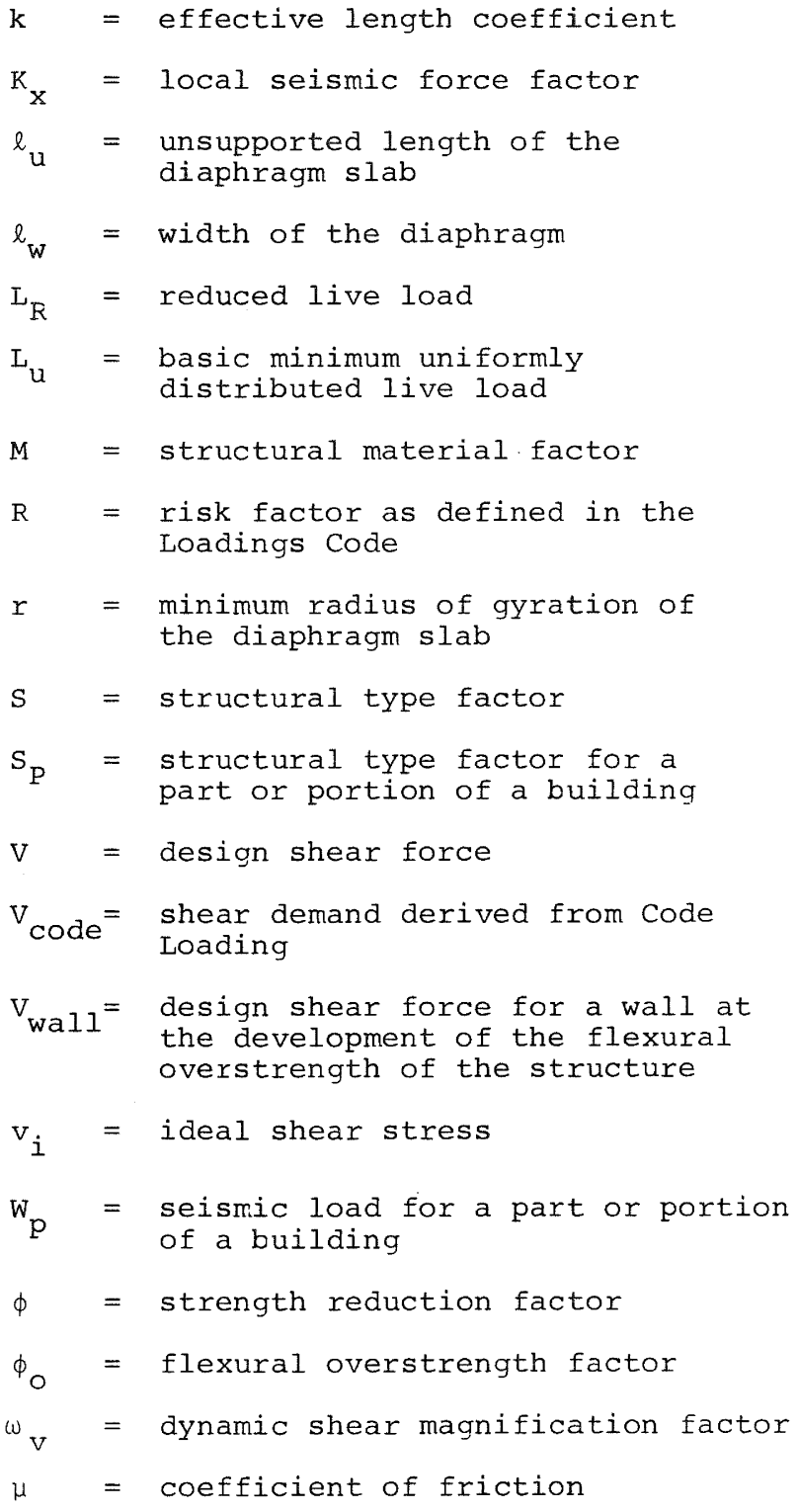

REFERENCES :

1. NZS 4203 : 1976, "Code of Practice for General Structural Design and Design Loadings for Buildings", Standards Association of New Zealand, $80 \mathrm{pp}$.

2. Park, R. and Paulay, T., "Reinforced Concrete Structures", John Wiley and Sons, New York, 1975, 769 pp.

3. Taylor, R.G., "Introduction to and Aims in the Design of Earthquake Resisting Shear Wall Structures" Section Aof the Shear Wall Study Group of the New Zealand National Society for Earthquake Engineering, The Bulletin of the New Zealand National Society for Earthquake Engineering, Vol. 13, No. 21980.

4. Robinson, L.M., "Shear Walls of Limited Ductility", Section C of the Shear Wall Study Group of New Zealand National Society for Earthquake Engineering, The Bulletin of the New Zealand National Society for Earthquake Engineering Vol. 13, No.2 1980 
5. DZ 3101 : Part $I$ and Part 2, Draft New Zealand Standard Code of Practice for the Design of Concrete Structures, Standards Association of New Zealand, 1978 .

6. Paulay, T. "Columns - Evaluation of Actions", The Bulletin of the New Zealand National Society for Earthquake Engineering, Vol. 10, No.2 June 1977. 